Original Article

\title{
Early reduction in toe flexor strength is associated with physical activity in elderly men
}

\author{
Masataka Suwa, $\mathrm{PhD}^{1,2)^{*}}$, Takayuki Imoto, $\mathrm{PhD}^{1)}$, Akira Kida, $\mathrm{MT}^{1)}$, \\ TAKASHI YOKOCHI, MD, $\mathrm{PhD}^{1)}$ \\ 1) Health Support Center WELPO, Toyota Motor Corporation: 1-1 Ipponmatsu, Iwakura-cho, Toyota, \\ Aichi 444-2225, Japan \\ 2) Faculty of Life Design, Tohoku Institute of Technology, Japan
}

\begin{abstract}
Purpose] To compare the toe flexor, hand grip and knee extensor strengths of young and elderly men, and to examine the association between toe flexor strength and physical activity or inactivity levels. [Subjects and Methods] Young ( $\mathrm{n}=155,18-23$ years) and elderly $(\mathrm{n}=60,65-88$ years) men participated in this study. Toe flexor, hand grip, and knee extensor strength were measured. Physical activity (time spent standing/walking per day) and inactivity (time spent sitting per day) were assessed using a self-administered questionnaire. [Results] Toe flexor, hand grip, and knee extensor strength of the elderly men were significantly lower than those of the young men. Standing/walking and sitting times of the elderly men were lower than those of the young men. Toe flexor strength correlated with hand grip and knee extensor strength in both groups. In elderly men, toe flexor strength correlated with standing/walking time. In comparison to the young men's mean values, toe flexor strength was significantly lower than knee extensor and hand grip strength in the elderly group. [Conclusion] The results suggest that agerelated reduction in toe flexor strength is greater than those of hand grip and knee extensor strengths. An early loss of toe flexor strength is likely associated with reduced physical activity in elderly men. Key words: Toe grip, Aging, Muscle strength
\end{abstract}

(This article was submitted Dec. 7, 2015, and was accepted Feb. 1, 2016)

\section{INTRODUCTION}

Toe flexor strength is a combination of the activity of plantar intrinsic (flexor hallucis brevis, flexor digitorum brevis, and lumbricales pedis) and extrinsic (flexor hallucis longus and flexor digitorum longus) muscles ${ }^{1)}$. Toe flexor muscles play important roles in arch support ${ }^{2,3)}$, standing ${ }^{4)}$, walking/running performance ${ }^{5-9)}$, and jump performance ${ }^{9}$, 10). Reduced toe flexor muscle force and/or volume are associated with foot and toe abnormalities including plantar fasciitis ${ }^{11)}$, pes cavus in Charcot-Marie-Tooth disease ${ }^{12)}$, and claw and hammer toe deformities ${ }^{13)}$. Furthermore, reduced toe flexor strength is a risk factor of falls for elderly persons ${ }^{14-16)}$. Thus, estimation of toe flexor strength may be important in the development of physical fitness, activities of daily living, and preventive care for elderly persons.

Skeletal muscle strength and volume decrease with age ${ }^{17,18)}$, and such decreases result in reduced physical abilities in older persons ${ }^{19)}$. The rate of the age-related reduction in skeletal muscle strength and volume differs among regions and muscles. The muscle strength and volume of the lower body decreases faster than those of the upper body ${ }^{20-22)}$. It is hypothesized that this age-related region-specific reduction is partially accounted for by an age-related reductions in physical activity ${ }^{21)}$.

Toe flexor strength also decreases with age ${ }^{4,23}$. Specifically, it has been shown to significantly reduce after the age of 50 in both men and women ${ }^{23}$. However, the rate of age-related reduction in toe flexor strength relative to other muscle strengths is unknown. Furthermore, the relationship between toe flexor strength and physical activity and inactivity in elderly men has not been investigated. Thus, the purpose of the present study was to compare the toe flexor strength and other muscle

\footnotetext{
*Corresponding author. Masataka Suwa (E-mail: masataka_suwa@mail.toyota.co.jp)

(C)2016 The Society of Physical Therapy Science. Published by IPEC Inc.

This is an open-access article distributed under the terms of the Creative Commons Attribution Non-Commercial No Derivatives (by-nc-nd) License $<$ http://creativecommons.org/licenses/by-nc-nd/4.0/>.
} 

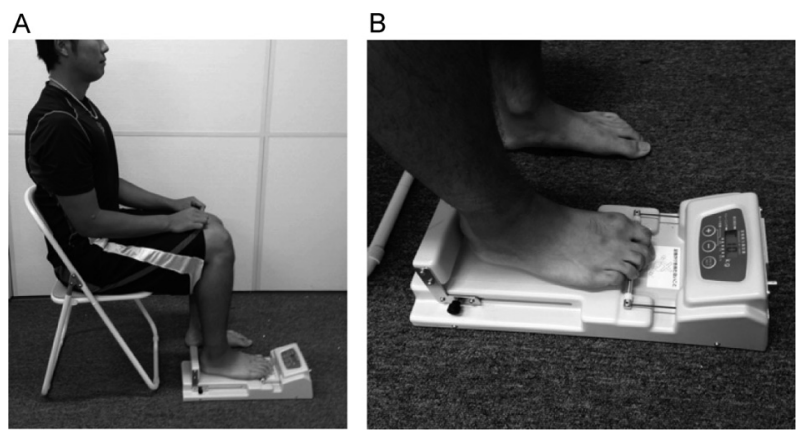

Fig. 1. Measurement of toe flexor strength

(A) The posture adopted during measurement of toe flexor strength. The subjects sat on a chair with the trunk in the vertical position, with the hip and knee joints flexed at approximately $90^{\circ}$, and the ankle joints in the neutral position (at approximately $90^{\circ}$ ). (B) Test of toe flexor strength using a toe grip dynamometer. One foot was placed on the dynamometer, and the first proximal phalanx of the foot was positioned on the grip bar with the heel position fixed using a heel stopper.

strengths of young and elderly men. Whether or not toe flexor strength was associated with physical activity/inactivity levels was also investigated.

\section{SUBJECTS AND METHODS}

A total of 155 young men (18-23 years) and 60 elderly men (65-88 years) participated in this study. The young men were recruited on a university campus. The elderly men were recruited from among participants in events run by public bodies or the Tohoku Institute of Technology. All subjects provided their written informed consent to participation in this study. This study was approved by the Ethical Committee of the Tohoku Institute of Technology.

Toe flexor strength was measured using a toe grip dynamometer (T.K.K. 3161, Takei Scientific Instruments Co., Ltd., Niigata, Japan). The intra-rater and inter-rater reliabilities of this apparatus have previously been reported ${ }^{24)}$. The subjects sat on a chair with the trunk in the vertical position, the hip and knee joints flexed at approximately $90^{\circ}$, and the ankle joints in a neutral position (at approximately $90^{\circ}$ ) (Fig. 1A). Previous studies have demonstrated that this position is the most suitable for measuring toe flexor strength, because of its reliability, the stability of the knee and ankle joints, and the ability of subjects to exert maximum force ${ }^{25-28)}$. The first proximal phalanx of the foot was positioned on a grip bar, and the heel position was fixed using a heel stopper (Fig. 1B). After sufficient practice, toe flexor strength was measured twice. Measurements were performed of the right and left toes, and the mean maximum force of each foot was used in analyses.

Hand grip strength was measured using a hand grip dynamometer (T.K.K. 5401, Takei Scientific Instruments). Measurements were made in duplicate on both hands, and the mean maximum force of each hand was used in the analyses.

Knee extensor strength was measured using a strain gauge (T.K.K. 5710e, Takei Scientific Instruments). The subjects sat on a seat (T.K.K. 5715, Takei Scientific Instruments) with the trunk in the vertical position and the hip and knee joints flexed at approximately $90^{\circ}$. A researcher put the subject's foot through the loop of the strap connected to the strain gauge, and the ankle was hooked in the loop of strap. Measurements were performed on both legs, and the mean value of each leg was used in the analyses.

Trunk flexibility was assessed using a sit-and-reach test using a device (T.K.K. 5412, Takei Scientific Instruments). The subjects sat on the floor with their hips, back, and the occipital region of the head touching a wall. Their legs lay straight at $90^{\circ}$ in front of the upper body. The zero point of the device was set in this position. They bent forward slowly, and as far forward as possible, pushing the device with both hands, and the distance moved by the device was measured. The measurements were performed twice, and the maximum value was used in the analyses.

Balance was assessed using the functional-reach test using a device (T.K.K. 5802, Takei Scientific Instruments). Measurements were made in duplicate, and the maximum value was used in the analyses.

Physical activity and inactivity levels were assessed using a self-administered questionnaire ${ }^{29)}$. Briefly, the mean daily sum of standing and walking times and sitting time during the last six months were requested.

Values are mean $\pm \mathrm{SD}$. The unpaired t-test was used to compare the means of the young and elderly groups. To compare percent differences of the elderly group mean values with the young group mean values of hand grip, knee extensor, and toe flexor strength, one-way analysis of variance (ANOVA) was used. The significance of between-group differences was determined using Tukey's post hoc test when the overall ANOVA was significant. Differences were considered significant when $\mathrm{p}<0.05$. SPSS software (Version 23.0 for Windows, SPSS Inc., Chicago, IL, USA) was used for all statistical analyses. 
Table 1. Subject characteristics

\begin{tabular}{lcc}
\hline & Young & Elderly \\
\cline { 2 - 3 } & $\mathrm{n}=155$ & $\mathrm{n}=60$ \\
\hline Age $(\mathrm{yrs})$ & $20.6 \pm 1.2$ & $73.6 \pm 5.2^{*}$ \\
Height $(\mathrm{cm})$ & $171.3 \pm 5.9$ & $163.4 \pm 4.5^{*}$ \\
Body weight $(\mathrm{kg})$ & $66.3 \pm 10.4$ & $62.4 \pm 8.7^{*}$ \\
BMI $\left(\mathrm{kg} / \mathrm{m}^{2}\right)$ & $22.6 \pm 3.2$ & $23.3 \pm 2.9$ \\
Hand grip strength $(\mathrm{kg})$ & $44.5 \pm 7.0$ & $35.2 \pm 6.0^{*}$ \\
Knee extensor strength $(\mathrm{kg})$ & $41.4 \pm 10.7$ & $26.6 \pm 7.9^{*}$ \\
Toe flexor strength $(\mathrm{kg})$ & $15.2 \pm 4.8$ & $8.4 \pm 3.9^{*}$ \\
Sit-and-reach (cm) & $40.3 \pm 9.9$ & $31.2 \pm 13.3^{*}$ \\
Functional reach $(\mathrm{cm})$ & $44.2 \pm 9.4$ & $32.2 \pm 9.9^{*}$ \\
Standing/walking time (hr/day) & $6.0 \pm 3.2$ & $3.9 \pm 2.4^{*}$ \\
Sitting time (hr/day) & $7.4 \pm 3.7$ & $6.2 \pm 3.3^{*}$ \\
\hline
\end{tabular}

BMI: body mass index. ${ }^{*} \mathrm{p}<0.05$ vs. young group

Table 2. Proportional differences in muscle strength of elderly men compared with the mean values of young men

\begin{tabular}{lccc}
\hline & Hand grip & Knee extensor & Toe flexor \\
\hline Proportional difference from young mean, \% & $79.2 \pm 13.4$ & $64.3 \pm 19.0^{*}$ & $55.2 \pm 22.4^{*} \dagger$ \\
\hline
\end{tabular}

$\mathrm{N}=60$. Proportional difference from young mean was calculated using the formula bellow:

proportional difference from young mean $(\%)=\mathrm{kg}$ old group $\bullet \mathrm{kg}$ mean value of young group ${ }^{-1} \bullet 100$.

Data are means $\pm \mathrm{SD} .{ }^{*} \mathrm{p}<0.05$ vs. hand grip strength. ${ }^{\dagger} \mathrm{p}<0.05$ vs. knee extensor strength

Table 3. Correlation coefficients (r) between toe flexor strength and the other parameters of both groups

\begin{tabular}{lcc}
\hline & Young & Elderly \\
\hline Age & $0.174^{*}$ & $-0.390^{*}$ \\
Height & 0.126 & 0.138 \\
Body weight & $0.225^{*}$ & 0.216 \\
BMI & $0.187^{*}$ & 0.194 \\
Hand grip strength & $0.317^{*}$ & $0.509^{*}$ \\
Knee extensor strength & $0.246^{*}$ & $0.590^{*}$ \\
Sit-and-reach & 0.108 & $0.389^{*}$ \\
Functional-reach & $0.240^{*}$ & $0.395^{*}$ \\
Standing/walking time & 0.113 & $0.276^{*}$ \\
Sitting time & -0.057 & -0.066 \\
\hline
\end{tabular}

BMI: body mass index. *Significant correlation with toe flexor strength $(\mathrm{p}<0.05)$

\section{RESULTS}

Table 1 shows the characteristics of the subjects. The mean height and body weight of the elderly group were significantly lower than those of the young group; body mass index (BMI) was not different between the two groups. Regarding the physical fitness parameters, all five measures of the elderly group (hand grip strength, knee extensor strength, toe flexor strength, sit-and-reach, and the functional-reach test) were significantly lower than those of the young group. Both the times spent standing/walking and sitting by the elderly group were significantly shorter than those of the young group.

Table 2 demonstrates the percent differences in the muscle strengths of the elderly men compared with the mean values of the young men. The rank-order of relative values of muscle strength was: toe flexor $<$ knee extensor $<$ hand grip $(\mathrm{p}<0.05)$.

Table 3 shows the correlation coefficients between toe flexor strength and other parameters in each group. In the young group, toe flexor strength was found to have significant positive correlations with age, body weight, BMI, hand grip strength, knee extensor strength and functional reach, but not height, sit-and-reach, and standing/walking and sitting times. In the elderly group, toe flexor strength was found to have a significant negative correlation with age, and significant positive 
correlations with hand grip strength, knee extensor strength, sit-and-reach, functional-reach, and standing/walking time; no correlation was found between toe flexor strength and height, body weight, BMI, or sitting time.

\section{DISCUSSION}

This study found that toe flexor strength decreases with increasing age, and hand grip and knee extensor strength also decrease. The rate of decrease of toe flexor strength with age was greater than those of other muscle strengths. In addition, toe flexor strength was positively associated with physical activity levels assessed by daily standing/walking time.

The rate of age-related reductions in toe flexor and knee extensor strengths were found to be greater than in hand grip strength. This is consistent with results reported by previous studies, which suggests that the muscle strength of the lower body decreases faster than the upper body ${ }^{20,22)}$. Moreover, the rate of age-related reduction in toe flexor strength was greater than that of knee extensor strength. The obvious conclusion to be drawn from this is that the aging process is reflected more by toe flexor strength than by other muscle strengths. However, the results do not mean that age-related decay in muscles involving toe joint movement is greater than in muscles involving knee joint movement, because this study did not measure toe extensor or knee flexor strength. The rate of age-related reduction in muscle volume differs among joint movement types. For example, the volume of the elbow flexor muscle decreases with age, whereas elbow extensor muscle volume does not ${ }^{30)}$. Additionally, the age-related reduction in knee extensor muscle volume is greater than that in knee flexor muscle volume $^{31)}$. Thus, it is likely that the rate of age-related decline in force production also differs among joint movement types. Unfortunately, there are few accurate methods to measure toe muscle strength other than that for toe flexion ${ }^{1)}$. Further studies are needed to estimate and compare the rates of age-related reductions in the muscle strengths of various types of actions and joints.

Toe flexor strength is linked with standing/walking performances. For example, toe flexor strength was found to positively associate with walking performance such as walking speed, percentage of swing time in a gait cycle, and stride length during walking at maximal speed, in elderly men and women ${ }^{5}$. Study also found that toe flexor strength showed a positive correlation with the physical activity level, estimated from the self-reported daily standing/walking time in elderly men. One plausible explanation for this correlation is that toe flexor muscles are intensely recruited during standing and/or walking actions leading to improvement of force production in these muscles. Indeed, activity of the flexor digitorum brevis muscle, estimated from intra-muscular electromyography, was shown to increase with increasing postural demand during standing ${ }^{32)}$. Furthermore, the long and short toe flexor muscles were shown to exert forces of approximately $61 \%$ and $49 \%$ of body weight, respectively, during the second peak of ground reaction force in the gait cycle ${ }^{33}$. Another potential explanation is that higher toe flexor strength supports activities of daily living, leading to an increase in standing/walking activity.

As mentioned above, toe flexion is closely related to standing and walking activity. Our study also found that the mean daily standing/walking time of elderly men was $35 \%$ lower than that of young men. It is likely that the age-related reduction in standing/walking activity has a greater impact on toe flexion strength than reductions in hand grip or knee extensor strength, leading to earlier loss of toe flexor strength than in other muscle strengths. Additionally, age-related decline in muscle strength is multifactorial ${ }^{18,34)}$, and the rate of decline in neuromuscular anatomical factors differs between the upper and lower body. For example, the proportion of fast-twitch type II fiber areas in the vastus lateralis muscle reduces with age faster than in the biceps brachii muscle ${ }^{35)}$. Moreover, the number of muscle fibers in the vastus lateralis muscle reduces with age ${ }^{36)}$, but does not in the biceps brachii muscle ${ }^{37)}$. The number of medial gastrocnemius motoneurons decreases with age, but the number of ulnar motoneurons in rats does not ${ }^{38}$. Although the present and other previous studies have not investigated such factors with regard to toe flexion, it is possible that such factors are associated with the early reduction of toe flexor strength observed in this study.

Certain limitations of the current study must be acknowledged. First, the cross-sectional nature of this study limits our ability to draw causal inferences from the relationships observed. It is still unclear whether increasing the physical activity level promotes the enhancement of toe flexor strength, or whether higher toe flexor strength promotes increases in the physical activity of elderly men. Further longitudinal studies are needed to fully understand the relationship between toe flexor strength and physical activity. Second, participants were not randomly sampled, as all of the participants were volunteers and able-bodied community-dwelling persons. Thus, there may be some bias in the characteristics of the participants. Third, the participants of this study were men. It is still not known whether the differences in the rate of age-related reduction in muscle strength among toe flexion, hand grip, and knee flexion are the same for women. Gender differences concerning age-related reductions in muscle force generation and volume have not been previously reported ${ }^{21,39)}$. Additionally, a previous study showed that toe flexor strength of male subjects in their $70 \mathrm{~s}$ was $38.5 \%$ lower than in that of the males in their $20 \mathrm{~s}$, but $29.8 \%$ lower in women ${ }^{23)}$, suggesting that the age-related reduction in toe flexor strength could be lower in women than in men. Fourth, this study examined young (18-23 years) and elderly (65-88 years) men, but not middle-aged men. Lynch et al. ${ }^{40)}$ demonstrated that elbow flexion force linearly decreased with age, whereas knee extension force decreased in a quadratic way. The possibility that different relationships of age-related decline among muscle groups impact the relative decline levels of the toe flexor, hand grip, and knee extensor strengths cannot be ruled out. Fifth, physical activity was estimated using a self-administered questionnaire which is considered a less reliable and valid method. It has been reported that questionnaires often over- or underestimate physical activity level due to recall bias ${ }^{41)}$. 
Despite these limitations, this study is the first to demonstrate the early loss of toe flexor strength compared to other muscle strengths, and the relationship between toe flexor strength and the physical activity levels of elderly men. It has been reported that elderly persons with poor toe flexor strength have difficulty walking safely under certain conditions ${ }^{5)}$. Thus, toe flexor strength should be considered a good indicator of muscle function and the physical fitness of elderly persons.

\section{REFERENCES}

1) Soysa A, Hiller C, Refshauge K, et al.: Importance and challenges of measuring intrinsic foot muscle strength. J Foot Ankle Res, 2012, 5: 29. [Medline] [CrossRef]

2) Wu L: Nonlinear finite element analysis for musculoskeletal biomechanics of medial and lateral plantar longitudinal arch of Virtual Chinese Human after plantar ligamentous structure failures. Clin Biomech (Bristol, Avon), 2007, 22: 221-229. [Medline] [CrossRef]

3) Tashiro Y, Fukumoto T, Uritani D, et al.: Children with flat feet have weaker toe grip strength than those having a normal arch. J Phys Ther Sci, 2015, 27: 3533-3536. [Medline] [CrossRef]

4) Endo M, Ashton-Miller JA, Alexander NB: Effects of age and gender on toe flexor muscle strength. J Gerontol A Biol Sci Med Sci, 2002, 57: M392-M397. [Medline] [CrossRef]

5) Misu S, Doi T, Asai T, et al.: Association between toe flexor strength and spatiotemporal gait parameters in community-dwelling older people. J Neuroeng Rehabil, 2014, 11: 143. [Medline] [CrossRef]

6) Mann R, Inman VT: Phasic activity of intrinsic muscles of the foot. J Bone Joint Surg Am, 1964, 46: 469-481. [Medline]

7) Rolian C, Lieberman DE, Hamill J, et al.: Walking, running and the evolution of short toes in humans. J Exp Biol, 2009, 212: 713-721. [Medline] [CrossRef]

8) Goldmann JP, Brüggemann GP: The potential of human toe flexor muscles to produce force. J Anat, 2012, 221: 187-194. [Medline] [CrossRef]

9) Morita N, Yamauchi J, Kurihara T, et al.: Toe flexor strength and foot arch height in children. Med Sci Sports Exerc, 2015, 47: 350-356. [Medline] [CrossRef]

10) Goldmann JP, Sanno M, Willwacher S, et al.: The potential of toe flexor muscles to enhance performance. J Sports Sci, 2013, 31: 424-433. [Medline] [CrossRef]

11) Chang R, Kent-Braun JA, Hamill J: Use of MRI for volume estimation of tibialis posterior and plantar intrinsic foot muscles in healthy and chronic plantar fasciitis limbs. Clin Biomech (Bristol, Avon), 2012, 27: 500-505. [Medline] [CrossRef]

12) Gallardo E, García A, Combarros O, et al.: Charcot-Marie-Tooth disease type 1 A duplication: spectrum of clinical and magnetic resonance imaging features in leg and foot muscles. Brain, 2006, 129: 426-437. [Medline] [CrossRef]

13) Myerson MS, Shereff MJ: The pathological anatomy of claw and hammer toes. J Bone Joint Surg Am, 1989, 71: 45-49. [Medline]

14) Murata S, Tsuda A: A prospective study of the relationship between physical and cognitive factors and falls in the elderly disabled at home. J Jpn Phys Ther Assoc, 2006, 33: 97-104 in Japanese.

15) Menz HB, Morris ME, Lord SR: Foot and ankle risk factors for falls in older people: a prospective study. J Gerontol A Biol Sci Med Sci, 2006, 61: 866-870. [Medline] [CrossRef]

16) Mickle KJ, Munro BJ, Lord SR, et al.: ISB Clinical Biomechanics Award 2009: toe weakness and deformity increase the risk of falls in older people. Clin Biomech (Bristol, Avon), 2009, 24: 787-791. [Medline] [CrossRef]

17) Delmonico MJ, Harris TB, Visser M, et al.: Health, aging, and body: longitudinal study of muscle strength, quality, and adipose tissue infiltration. Am J Clin Nutr, 2009, 90: 1579-1585. [Medline] [CrossRef]

18) Doherty TJ: Invited review: aging and sarcopenia. J Appl Physiol 1985, 2003, 95: 1717-1727. [Medline] [CrossRef]

19) Dufour AB, Hannan MT, Murabito JM, et al.: Sarcopenia definitions considering body size and fat mass are associated with mobility limitations: the Framingham Study. J Gerontol A Biol Sci Med Sci, 2013, 68: 168-174. [Medline] [CrossRef]

20) Asmussen E, Heebøll-Nielsen K: Isometric muscle strength in relation to age in men and women. Ergonomics, 1962, 5: 167-169. [CrossRef]

21) Janssen I, Heymsfield SB, Wang ZM, et al.: Skeletal muscle mass and distribution in 468 men and women aged 18-88 yr. J Appl Physiol 1985, 2000, 89: 81-88. [Medline]

22) Bemben MG, Massey BH, Bemben DA, et al.: Isometric muscle force production as a function of age in healthy 20- to 74-yr-old men. Med Sci Sports Exerc, 1991, 23: 1302-1310. [Medline]

23) Uritani D, Fukumoto T, Matsumoto D, et al.: Reference values for toe grip strength among Japanese adults aged 20 to 79 years: a cross-sectional study. J Foot Ankle Res, 2014, 7: 28. [Medline] [CrossRef]

24) Uritani D, Fukumoto T, Matsumoto D: Intrarater and interrater reliabilities for a toe grip dynamometer. J Phys Ther Sci, 2012, 24: 639-643. [CrossRef]

25) Soma M, Murata S, Kai Y, et al.: An examination of limb position for measuring toe-grip strength. J Phys Ther Sci, 2014, 26: 1955-1957. [Medline] [CrossRef]

26) Soma M, Murata S, Kai Y, et al.: Activity of the femoral muscles during toe-gripping action. J Phys Ther Sci, 2014, 26: 1619-1621. [Medline] [CrossRef]

27) Soma M, Murata S, Kai Y, et al.: Kinematic analysis during toe-gripping strength exertion: angular changes in the ankle joint and leg muscle activities. J Phys Ther Sci, 2015, 27: 1957-1960. [Medline] [CrossRef]

28) Soma M, Murata S, Kai Y, et al.: The activities of the muscles around the ankle joint during foot-gripping are affected by the angle of the ankle. J Phys Ther Sci, 2013, 25: 1625-1627. [Medline] [CrossRef]

29) Hatayama $\mathrm{T}$, Une $\mathrm{H}$, Yoshitake $\mathrm{Y}$, et al.: A prospective study on the relationship between physical difficulties and mental problems and falls in communitydwelling elderly. Jpn J Health Prom, 2004, 6: 123-131 in Japanese.

30) Candow DG, Chilibeck PD: Differences in size, strength, and power of upper and lower body muscle groups in young and older men. J Gerontol A Biol Sci Med Sci, 2005, 60: 148-156. [Medline] [CrossRef]

31) Ogawa M, Yasuda T, Abe T: Component characteristics of thigh muscle volume in young and older healthy men. Clin Physiol Funct Imaging, 2012, 32: 89-93. [Medline] [CrossRef]

32) Kelly LA, Kuitunen S, Racinais S, et al.: Recruitment of the plantar intrinsic foot muscles with increasing postural demand. Clin Biomech (Bristol, Avon), 
2012, 27: 46-51. [Medline] [CrossRef]

33) Jacob HA: Forces acting in the forefoot during normal gait - an estimate. Clin Biomech (Bristol, Avon), 2001, 16: 783-792. [Medline] [CrossRef]

34) Aagaard P, Suetta C, Caserotti P, et al.: Role of the nervous system in sarcopenia and muscle atrophy with aging: strength training as a countermeasure. Scand J Med Sci Sports, 2010, 20: 49-64. [Medline] [CrossRef]

35) Aoyagi Y, Shephard RJ: Aging and muscle function. Sports Med, 1992, 14: 376-396. [Medline] [CrossRef]

36) Lexell J, Taylor CC, Sjöström M: What is the cause of the ageing atrophy? Total number, size and proportion of different fiber types studied in whole vastus lateralis muscle from 15- to 83-year-old men. J Neurol Sci, 1988, 84: 275-294. [Medline] [CrossRef]

37) Klein CS, Marsh GD, Petrella RJ, et al.: Muscle fiber number in the biceps brachii muscle of young and old men. Muscle Nerve, 2003, 28: 62-68. [Medline] [CrossRef]

38) Hashizume K, Kanda K: Neuronal dropout is greater in hindlimb motor nuclei than in forelimb motor nuclei in aged rats. Neurosci Lett, 1990, 113: 267-269. [Medline] [CrossRef]

39) Lindle RS, Metter EJ, Lynch NA, et al.: Age and gender comparisons of muscle strength in 654 women and men aged 20-93 yr. J Appl Physiol 1985, 1997, 83: 1581-1587. [Medline]

40) Lynch NA, Metter EJ, Lindle RS, et al.: Muscle quality. I. Age-associated differences between arm and leg muscle groups. J Appl Physiol 1985, 1999, 86: 188-194. [Medline]

41) Kowalski K, Rhodes R, Naylor PJ, et al.: Direct and indirect measurement of physical activity in older adults: a systematic review of the literature. Int J Behav Nutr Phys Act, 2012, 9: 148. [Medline] [CrossRef] 